\section{Revista Brasileira de Administração Científica}

Brazilian Journal of Scientific Administration

Jul a Set $2020-v .11-n .3$
ISSN: 2179-684X

\title{
A relevância da fraude contábil ocorrida na Via Varejo S.A.: um estudo de eventos
}

A partir de novembro de 2019 a Via Varejo S.A. iniciou uma investigação interna independente cuja conclusão indicou a ocorrência de fraudes e erros contábeis com impacto nos demonstrativos contábeis daquele ano de $R \$ 1,19$ bilhão. Ao longo da investigação foram divulgadas ao mercado informações a seu respeito pela Via Varejo S.A. e sua antiga controladora - Cia Brasileira de Distribuição. O objetivo deste trabalho é, justamente, verificar a relevância dessas informações pertinentes à fraude contábil ocorrida na Via Varejo S.A. Para tanto, foi empreendido um estudo de eventos do retorno das ações das empresas envolvidas, quais sejam, as próprias Via Varejo S.A. e Cia Brasileira de Distribuição, nas datas de divulgação daquelas informações pertinentes à fraude contábil em questão. Os resultados apontam diversos retornos anormais nos ativos sob análise nas janelas de eventos, indicando a relevância da divulgação de informações relacionadas à fraude contábil ocorrida na Via Varejo S.A.. Conforme predito, nas ações da Cia Brasileira de Distribuição predominaram os retornos anormais negativos. Por outro lado, nas ações da Via Varejo S.A. predominaram os retornos anormais positivos, inobstante haver indícios de uma reação inicial incerta dos agentes de mercado. O resultado inesperado em relação ao retorno das ações da Via Varejo S.A. pode decorrer de uma interpretação do mercado no sentido de que o modo como foi desvelada a fraude contábil pela Via Varejo S.A. representa um aprimoramento de seus mecanismos de Governança Corporativa.

Palavras-chave: Fraude Contábil; Relevância; Estudo de Eventos.

\section{The value relevance of the accounting fraud occurred at Via Varejo S.A.: an event study}

\begin{abstract}
As of November 2019, Via Varejo S.A. initiated an independent internal investigation whose conclusion indicated the occurrence of accounting fraud and errors with an impact on the financial statements of that year of $\mathrm{R} \$ 1.19$ billion. Throughout the investigation, information about Via Varejo S.A. and its former parent company - Cia Brasileira de Distribuição - was disclosed to the market. The objective of this paper is, precisely, to verify the value relevance of this information pertinent to the accounting fraud occurred in Via Varejo S.A. To this end, a event study of the return of the shares of the companies involved, namely Via Varejo S.A. and Cia Brasileira de Distribuição, was undertaken on the dates of disclosure of the information pertinent to the accounting fraud under analysis. The results point to several abnormal returns on the assets under analysis in the event windows, indicating the relevance of the disclosure of information related to accounting fraud that occurred in Via Varejo S.A.. As predicted, in the shares of Cia Brasileira de Distribuição the negative abnormal returns predominated. On the other hand, in the shares of Via Varejo S.A., positive abnormal returns predominated, despite signs of an uncertain initial reaction from market agents. The unexpected result regarding the return of Via Varejo S.A.'s shares may result from an interpretation of the market in the sense that the way in which accounting fraud was unveiled by Via Varejo S.A. represents an improvement in its corporate governance mechanisms.
\end{abstract}

Keywords: Accounting Fraud; Value Relevance; Event Study.

Topic: Contabilidade Geral

Reviewed anonymously in the process of blind peer.
Received: 09/06/2020

Approved: $\mathbf{3 0 / 0 7 / 2 0 2 0}$
João Henrique Krauspenhar (iD)

Universidade Federal de Santa Catarina, Brasil

http://lattes.cnpq.br/2691317038198259

http://orcid.org/0000-0002-6454-7748

joaohkrauspenhar@gmail.com

Suliani Rover (ii

Universidade Federal de Santa Catarina, Brasil

http://lattes.cnpq.br/6285577163747055

http://orcid.org/0000-0001-8612-2938

sulianirover@gmail.com
Referencing this:

KRAUSPENHAR, J. H.; ROVER, S.. A relevância da fraude contábil ocorrida na Via Varejo S.A.: um estudo de eventos. Revista Brasileira de Administração Científica, v.11, n.3, p.242-257, 2020. DOI: http://doi.org/10.6008/CBPC2179-684X.2020.003.0017 


\section{INTRODUÇÃO}

A ocorrência de fraudes é um problema real das organizações (MURCIA et al., 2007), existindo, muito provavelmente, desde os primórdios das relações comerciais há milhares de anos (DORMINEY et al., 2012). Robins (2012) relata o que pode ter sido a primeira fraude ocorrida em uma companhia aberta - Companhia Britânica das Índias Orientais - no final do século XVII.

O início do século XXI foi um período repleto de fraudes corporativas às quais foram conferidas grande destaque, como as que se passaram nas empresas Xerox (2000), Enron (2001), WorldCom (2002), Parmalat (2002) (MURCIA et al., 2007), Petrobras (2014) e Toshiba (2016) (CAPLAN et al., 2019). Mais recentemente, no Brasil, a Via Varejo S.A., companhia de capital aberto com ações ordinárias negociadas no Brasil, Bolsa, Balcão - B3 sob código VVAR3, passou a integrar esse rol.

Com efeito, em uma série de comunicados a partir do mês de novembro de 2019 - que serão melhor explorados adiante - a Via Varejo S.A. informou ao mercado a realização de investigação a respeito de erros e fraudes contábeis que culminaram em um impacto negativo no seu resultado do exercício findo em 31 de dezembro de 2019 no importe de R\$ 1.190 bilhão. É o que se extrai do Fato Relevante datado de 12 de dezembro de 2019 segundo o qual, até então, a investigação conduzida havia encontrado "(i) indícios de fraude contábil caracterizada pela manipulação da provisão trabalhista da Companhia e pelo diferimento indevido na baixa de ativos e contabilização de passivos; e (ii) falhas de controle interno que poderiam resultar em erros materiais de determinadas contas contábeis da Companhia" (VIA VAREJO S.A., 2019b). Estes acontecimentos receberam relevante cobertura da mídia especializada, com notícias referindo o impacto da investigação no preço das ações (PEREIRA, 2019) e o impacto bilionário nas demonstrações contábeis da Companhia.

Interessante notar que a Cia Brasileira de Distribuição, companhia aberta com ações ordinárias negociadas na B3 sob código PCAR3, esteve envolvida indiretamente nesses fatos, por ter sido a controladora da Via Varejo S.A. até junho de 2019, ou seja, no período em que os fatos tidos por fraudulentos ocorreram. Nesse sentido, também emitiu uma série de comunicados ao mercado e foi alvo da cobertura midiática no que diz respeito à sua eventual responsabilização.

Essa fraude contábil se soma a diversas outras ocorridas no ambiente corporativo. Com efeito, já no início do século XXI Rezaee (2005) informou que as fraudes contábeis haviam custado mais de US\$500 bilhões nos anos anteriores. Na mesma linha, um relatório a respeito de demonstrações financeiras fraudulentas elaborado a pedido do Committee of Sponsoring Organizations of the Treadway Commission - COSO (BEASLEY et al., 2010) apontou que o valor médio das fraudes analisadas em companhias abertas norteamericanas era de US\$397 milhões. No Brasil, estudo da PWC (2018) a respeito de fraudes e crimes econômicos aponta que $22 \%$ deles consistem em fraudes contábeis. Esses números são um indício da materialidade assumida pela fraude corporativa e, mais especificamente, contábil em âmbito mundial e nacional.

Quanto às consequências decorrentes dos atos fraudulentos, Smith (1776) já apontava a potencial 
erosão de valor aos acionistas, o que é confirmado pelo relatório já mencionado da COSO no ponto em que indica a presença de retornos anormais negativos no preço de ações de companhias relacionadas a esses fatos (BEASLEY et al., 2010). Fich et al. (2007) destacaram o impacto das fraudes corporativas à reputação das empresas e pessoas envolvidas, mencionando a existência de custo reputacional. Por outro lado, nem sempre o mercado de capitais enxerga as fraudes como igualmente ofensivas ao valor das entidades, reagindo diferentemente conforme a natureza e o grau de seriedade de cada caso (DAVIDSON et al., 1994).

É na consideração conjunta da materialidade e potenciais consequências das fraudes contábeis, que se justifica a presente pesquisa, atendendo ao interesse acadêmico de investigar os reflexos de escândalos corporativos às empresas envolvidas (BARROS et al., 2019).

Dado o seu viés contábil, o objetivo desta pesquisa consistente em verificar a relevância da divulgação de informações pertinentes à fraude contábil ocorrida na Via Varejo S.A. A relevância é uma das características qualitativas fundamentais da informação contábil, estando presente quando esta tem valor preditivo, confirmatório, ou ambos, ou seja, quando for capaz de fazer a diferença na tomada de decisão pelos usuários (CPC, 2019).

Para tanto, foi empreendido um estudo de eventos do retorno das ações das empresas envolvidas, quais sejam, a própria Via Varejo S.A. e a Cia Brasileira de Distribuição - sua antiga controladora -, nas datas de divulgação das principais informações pertinentes à fraude contábil em questão. Este método é adequado à mensuração do impacto de determinado evento no valor das entidades (MACKINLAY, 1997), capturando, assim, a relevância quando o evento em questão disser respeito à divulgação de uma informação contábil.

A sequência do trabalho está dividida em quatro seções. A primeira apresenta a revisão da bibliografia pertinente à fraude corporativa e contábil in abstracto, à fraude ocorrida na Via Varejo S.A., à relevância contábil e aos estudos anteriores relacionados ao presente, bem como o desenvolvimento das hipóteses. A segunda aborda os aspectos metodológicos do trabalho, notadamente os passos do estudo de eventos empreendido. A terceira compreende a análise dos resultados obtidos com a realização do estudo de eventos. Por fim, a quarta apresenta as conclusões do trabalho.

\section{REVISÃO TEÓRICA}

\section{Fraude corporativa e contábil}

A fraude consubstancia-se em qualquer ação ou omissão cometida de forma planejada com a finalidade de obter proveito em detrimento de terceiros (MURCIA et al., 2007). Em sentido semelhante, Borges et al. (2019) a entendem como qualquer meio de obter vantagem injusta sobre outrem.

No que diz respeito à fraude corporativa - aquela cometida no âmbito de organizações -, é preciso diferenciar três espécies de atos fraudulentos: corrupção, apropriação indevida de ativos e fraude nas demonstrações contábeis (ACFE, 2010). A primeira envolve uma ação de pessoa que detenha um cargo ou uma posição que lhe permita tirar alguma vantagem pessoal e que traga danos à organização que representa (BORGES et al., 2019). A segunda, por seu turno, ocorre com o uso indevido de ativos da organização para 
benefício próprio, enquanto a terceira relaciona-se à evidenciação adulterada de informações contábeis com a finalidade de beneficiar a organização (MURCIA et al., 2007). É a fraude nas demonstrações contábeis que será abordada nessa pesquisa.

No âmbito regulamentar, a Resolução 2016/NBCTA240(R1) do CFC (2016) dispõe que a fraude contábil envolve a falsificação de registros ou documentos que alterem os registros de contas patrimoniais e de resultado, a omissão do registro contábil de transações ou a aplicação imprópria de práticas contábeis. Importante destacar a passagem em que consigna que "A informação contábil fraudulenta, muitas vezes, é conseguida por distorção intencional de estimativas contábeis. Isso é conseguido, por exemplo, superestimando ou subestimando todas as provisões [...]" (CFC, 2016).

Rezaee (2005) conceitua a fraude contábil como uma atitude deliberada das corporações em enganar os usuários de suas demonstrações contábeis, especialmente investidores e credores, através do preparo e disseminação de informações contábeis materialmente distorcidas.

É preciso, no entanto, diferenciar a fraude contábil de erro na publicação das demonstrações contábeis e gerenciamento de resultado. Isso porque, ao passo que a fraude contábil é deliberada, o erro é involuntário (MURCIA et al., 2007). Quanto ao gerenciamento, esse se dá dentro dos limites da norma, ou seja, é feita uma opção entre alternativas contábeis legais, ainda que com vistas ao resultado da organização (WUERGES, 2010). Interessante notar, porém, que entidades que praticaram mais amplamente o gerenciamento de resultado em anos anteriores têm maior probabilidade de se envolverem em fraudes contábeis (PEROLS et al., 2011).

Aproveitando o ensejo, outras possíveis causas e motivações ao cometimento de fraudes contábeis envolvem a existência de poucos mecanismos de governança corporativa (FARBER, 2005) e pressões econômicas internas e externas (REZAEE, 2005), como expectativas dos proprietários e mercado em relação aos resultados e valorização das ações bem como dos responsáveis pelo seu cometimento em virtude da política de remuneração da empresa (BORGES et al., 2019).

Ironicamente, contudo, dentre as consequências à organização pelo desvelamento de fraudes destacam-se a perda de credibilidade e reputação, perda de valor aos investidores (FICH et al., 2007), aumento do custo de capital (DECHOW et al., 1996) e deslistagem de suas ações nas bolsas de valores (REZAEE, 2005). Aos responsáveis pelo seu cometimento, por seu turno, as consequências observadas são a devolução de suas compensações em ações, demissão, proibição de trabalhar em outra entidade de capital aberto e responsabilização penal (REZAEE, 2005).

Por outro lado, Davidson et al. (1994) apontam que o mercado não vê todas as fraudes de maneira semelhante, reagindo diferentemente em função da sua natureza e extensão. Importante destacar, também, que Farber (2005) aponta que as organizações tendem a aprimorar seus mecanismos de governança após a ocorrência de fraudes em seu interior, sendo que as companhias que adotam esses aprimoramentos têm um retorno das suas ações superior ao das companhias que não adotam.

O que fica, no entanto, é a advertência de Rezaee (2005) de que a fraude contábil é uma séria ameaça à confiança dos participantes de mercado na informação financeira, ou seja, nas demonstrações contábeis. 


\section{Fraude na Via Varejo S.A.}

Em 13 de novembro de 2019 a Via Varejo S.A. emitiu o Fato Relevante intitulado "Investigação Independente" em que informou o recebimento de "denúncias anônimas relativas a supostas irregularidades contábeis", bem como a constituição de "Comitê de Investigação" para a averiguação dos fatos denunciados. Apontou que a 1a fase das investigações, já finalizada, não havia confirmado as denúncias de irregularidades e no âmbito da $2 \underline{a}$ fase, ainda em andamento, nada havia sido descoberto que alterasse os resultados da $1 \underline{a}$ fase (VIA VAREJO S.A., 2019a). Nesse primeiro momento já foi referido na mídia especializada o impacto da divulgação na cotação das ações da Via Varejo S.A. (PEREIRA, 2019).

Na data de 12 de dezembro de 2019 a companhia emitiu outro Fato Relevante intitulado "Atualização Acerca da Investigação Independente" em que consignou os resultados da 2a fase de investigação, dentre os quais a presença de “(i) indícios de fraude contábil caracterizada pela manipulação da provisão trabalhista da Companhia e pelo diferimento indevido na baixa de ativos e contabilização de passivos; e (ii) falhas de controle interno que poderiam resultar em erros materiais de determinadas contas contábeis da Companhia". Informou, ainda, que a partir desses achados foi determinada a realização de uma 3 a fase da investigação e que o impacto estimado no resultado da Companhia era de $R \$ 1,05$ a $R \$ 1,2$ bilhão (VIA VAREJO S.A., 2019b).

Em função de a Cia Brasileira de Distribuição ter sido a controladora da Via Varejo S.A. até junho/2019 - ou seja, em período relevante de ocorrência das fraudes contábeis informadas por esta -, especulou-se a sua responsabilização, pelo que também emitiu Comunicado ao Mercado na mesma data de 12 de dezembro de 2019. Neste Comunicado apontou, em síntese, que à época do seu controle a administração da Via Varejo S.A. adotava critérios contábeis "uniformes e consistentes com as regras contábeis e regulamentares vigentes", que a as demonstrações contábeis "sempre foram auditadas anualmente e revisadas trimestralmente por auditores externos de elevada competência e reputação, pertencentes ao chamado grupo das 'Big4'”, bem como a existência de diversos órgãos de controle interno como Conselho Fiscal, Comitê de Auditoria e comitês auxiliares compostos, inclusive, por membros indicados pela "Família Michel Klein" que veio a adquirir o controle da Via Varejo S.A. dela (GPA, 2019).

Da parte da Via Varejo S.A., a situação culminou com a emissão em 25 de março de 2020 de Fato Relevante intitulado "Conclusão da Investigação Independente", em que complementou o comunicado anterior ao informar que "o valor final apurado dos ajustes às demonstrações financeiras do 4을 trimestre de 2019, decorrentes dos achados da Investigação, incluindo efeitos de fraudes, erros e mudanças de estimativa, é de $\mathrm{R} \$ 1,190$ bilhão (R\$ 786 milhões líquidos de impostos)" (VIA VAREJO S.A., 2020).

Ato contínuo a Cia Brasileira de Distribuição emitiu novo Comunicado ao Mercado em 26 de março de 2020 reiterando a sua conviç̧ão "quanto à inexistência de irregularidades e muito menos de quaisquer fraudes contábeis na contabilidade da Via Varejo S.A. no período que foi controlador da Via Varejo S.A." (GPA, 2020).

Tem-se, portanto, que a Investigação Independente conduzida pela Via Varejo S.A., a partir do 
recebimento de denúncias anônimas, desvelou fraudes corporativas, mais especificamente fraudes nas demonstrações contábeis, consistentes em manipulação da provisão trabalhista e diferimento indevido da baixa de ativos e contabilização de passivos no valor de $\mathrm{R} \$ 1,19$ bilhão. Consubstancia-se, assim, em fraude nas demonstrações contábeis decorrente da omissão do registro contábil de transações ou aplicação imprópria de práticas contábeis, nos termos da já citada Resolução 2016/NBCTA240(R1) (CFC, 2016).

Importante considerar, também, que pelo fato de as fraudes terem ocorrido sobretudo em período de controle da Via Varejo S.A. pela Cia Brasileira de Distribuição, repercutiram junto a esta, tendo ela sustentado sua ausência de reponsabilidade em mais de uma oportunidade. Ademais, houve repercussão na mídia especializada em relação às duas empresas, notadamente no que toca à extensão da fraude, consequência ao preço de suas ações e possíveis responsabilizações.

\section{Relevância, estudos de eventos pertinentes e desenvolvimento das hipóteses}

A relevância é uma das características qualitativas fundamentais da informação contábil. É tida por relevante a informação capaz de fazer a diferença nas decisões tomadas pelos usuários, o que é o caso quando tem valor preditivo ou confirmatório, ou ambos (CPC, 2019). Em termos de pesquisa contábil, um modo de aferir a relevância de determinada informação contábil a respeito de uma entidade é verificar a variação do preço das ações da respectiva empresa. Isso porque, se uma informação é útil, levará os tomadores de decisões a alterar suas crenças ou ações, afetando o preço das ações da companhia em questão (SCOTT, 2015).

Um meio de se fazer isso é por meio de um estudo de eventos, por este método proporcionar a mensuração do impacto de determinado evento no valor das entidades (MACKINLAY, 1997). Binder (1998) complementa que o estudo de eventos se tornou o método padrão para mensurar a reação do preço a alguma informação ou acontecimento, testando a hipótese de mercado eficiente referente à informação pública. Sob a ótica da relevância, infere-se se um fato contábil agrega conteúdo informacional aos agentes de mercado, através da análise da variação de preço e volume de negociações em um intervalo de tempo ao longo do evento (KOTHARI, 2001).

A pioneira pesquisa de Ball et al. (1968) consubstancia-se, justamente, no desenvolvimento de um estudo de eventos sob a perspectiva da relevância contábil, tendo fornecido evidências da reação do preço das ações ao anúncio de resultados das entidades. Ou seja, atestou o valor preditivo ou confirmatório, ou ambos, de informação contábil consistente em divulgação de resultados, posto que constatou a alteração no comportamento dos investidores a partir daquela.

Mais alinhados ao objeto deste estudo, Davidson et al. (1994) apontaram uma reação negativa do mercado ao anúncio de ilegalidades corporativas, tais quais corrupção, evasão fiscal, roubo de segredos, violação de contratos governamentais e fraudes contábeis. Quanto a essa última, interessante notar que foram constatadas reações negativas tanto no evento do anúncio da fraude, quanto no da realização de acusações pelos órgãos responsáveis.

Por outro lado, é importante considerar que determinadas espécies de fraudes não ensejaram reação 
negativa do mercado - na verdade, em algumas situações foi até positiva -, como é o caso de fixação de preços e cobrança excessiva de consumidores (DAVIDSON et al., 1994). Isso fornece evidências de que o mercado reage diferentemente às fraudes corporativas, conforme a natureza e extensão de cada caso.

Necessário considerar, também, outras pesquisas afins à presente, por empregarem um estudo de eventos e abordarem acontecimentos fraudulentos ou negativos às entidades. É o caso do estudo de Macedo et al. (2016), que investigou a reação do mercado a diversos eventos relacionados à divulgação de fraude corporativa ocorrida no banco HSBC, como notícias na mídia e a publicação de demonstrações contábeis. Seus achados apontam que foi justamente a divulgação das demonstrações contábeis que ensejou a maior reação do mercado, sendo considerada, portanto, o evento mais relevante.

Em sentido semelhante, Paul-Lawal (2016) estudou o impacto de eventos consistentes em anúncios de acusações de corrupção contra pessoas nigerianas nas empresas relacionadas a elas, tendo encontrado evidência de reação negativa do mercado.

Barros et al. (2019), por seu turno, investigaram o impacto da Operação Carne Fraca - que disse respeito a fraudes no processo produtivo de empresas brasileiras do setor de proteína animal - no valor das ações das principais empresas brasileiras e mexicanas desse setor, sob a ótica do efeito contágio. Os resultados indicam retornos anormais negativos e significativos nas empresas brasileiras, bem como positivos e significativos nas empresas mexicanas.

A pesquisa de Brown et al. (2015) aproxima-se desta por ter consistido em estudo de eventos de acidentes na indústria química. Os resultados apontam que as ações da empresa em que ocorreram os acidentes experimentaram retornos anormais negativos proporcionais ao número de pessoas prejudicadas. Interessante apontar, também, o estudo de Bash et al. (2019) que indicou o impacto negativo do desaparecimento do jornalista Jamal Khashogii - um fato político negativo - nas ações que compõem a Saudi Stock Exchange.

Conforme se observou nos estudos de eventos revisados, ocorre uma reação negativa do preço das ações de entidades envolvidas em fraudes e eventos negativos diversos, tais quais, corrupção (PAUL-LAWAL, 2016), evasão fiscal, roubo de segredos, violação de contratos governamentais, fraudes contábeis (DAVIDSON et al., 1994), fraude no processo produtivo (BARROS et al., 2019), acidentes químicos (BROWN et al., 2015) e fatos políticos negativos (BASH et al., 2019).

Isso está em linha com as potenciais consequências decorrentes de fraudes corporativas advertidas pela teoria, como a perda de valor aos investidores, representada pela queda do preço de suas ações (FICH et al., 2007). Em se tratando de fraudes contábeis, importante destacar novamente a advertência de Rezaae (2005) no sentido de que representam uma séria ameaça à confiança dos participantes de mercado nas informações contábeis.

Considerando isso e que a partir da revisão das informações disponibilizadas pela Via Varejo S.A., pela Cia Brasileira de Distribuição e pela mídia especializada, tem-se a ocorrência de fraude contábil na Via Varejo S.A. com repercussão junto à Cia Brasileira de Distribuição, por ser esta a entidade controladora daquela na época dos fatos fraudulentos, estabelecem-se as seguintes hipóteses de pesquisa: H1: os eventos 
consistentes na divulgação de informações relacionada à fraude contábil na Via Varejo S.A. são relevantes sob a perspectiva do preço das suas ações, afetando-o negativamente. $\mathrm{H} 2$ : os eventos consistentes na divulgação de informações relacionada à fraude contábil na Via Varejo S.A. são relevantes sob a perspectiva do preço das ações da Cia Brasileira de Distribuição, afetando-o negativamente.

\section{METODOLOGIA}

Já se adiantou que a metodologia de estudo de eventos é adequada à mensuração do impacto de determinado evento no valor das entidades (MACKINLAY, 1997), sendo comumente empregada para o teste da hipótese de eficiência dos mercados (BINDER, 1998) e de relevância da informação contábil (KOTHARI, 2001), tendo sido este, inclusive, o caso da pesquisa pioneira de Ball et al. (1968) a respeito da relevância do anúncio de resultados.

Em linha com o objetivo proposto, realizou-se um estudo de eventos a fim de verificar a relevância das informações relacionadas à fraude contábil ocorrida na Via Varejo S.A. a partir da reação do preço das suas ações e da Cia Brasileira de Distribuição, ambas negociadas na B3 sob o código, respectivamente, VVAR3 e PCAR3. Ambas são companhias varejistas tradicionais brasileiras, com mais de 60 anos de histórias cada uma, sendo a Via Varejo S.A. detentora de marcas como 'Ponto Frio' e 'Casas Bahia', ao passo que a Cia Brasileira de Distribuição é responsável pelas marcas 'Pão de Açúcar', 'Extra' e 'Assai', dentre outras.

Essas duas empresas, portanto, compõem a amostra empregada nesse estudo de eventos donde foram extraídos os dados pertinentes, notadamente a cotação de suas ações. Os dados foram obtidos da plataforma Economática, sendo as cotações ajustadas a desdobramentos, grupamentos e pagamento de dividendos. De acordo com Campbell et al. (1997) o primeiro passo de um estudo de eventos envolve a definição dos eventos de interesse e o período de análise, ou seja, a janela de evento.

In casu, os eventos que compõem o estudo são as divulgações de informações a respeito da fraude contábil na Via Varejo S.A.. Conforme se viu, a Via Varejo S.A. publicou Fatos Relevantes a respeito dessa questão nas datas de 13 de novembro de 2019, 12 de dezembro de 2019 e 25 de março de 2020, sendo consideradas estas, portanto, as datas de ocorrência dos eventos tidas por Data 0. Esses acontecimentos serão referidos doravante, respectivamente, como Evento 1, Evento 2 e Evento 3.

Em relação à quantidade de dias da janela de eventos, MacKinlay (1997) reconhece haver um componente subjetivo na sua determinação, sendo usual, no entanto, sua definição entre 3 e 5 dias em torno da Data 0. Optou-se pela escolha de 3 dias úteis anteriores e 3 dias úteis posteriores. Em relação Evento 1 tem-se, portanto, a seguinte representação da sua janela do evento.

Após, é preciso definir uma janela de estimação, que é o período utilizado para o cálculo dos parâmetros com base nos quais são estimados os retornos esperados e anormais. A escolha mais comum é um período anterior à janela de eventos, para que os parâmetros de estimação não sofram a influência do próprio evento (MACKINLAY, 1997). De acordo com Benninga (2014) o período de estimação mais usual é de 252 dias úteis, correspondente a um ano útil. Novamente em relação ao Evento 1, a janela de estimação é representada em relação à janela de eventos da seguinte forma. 


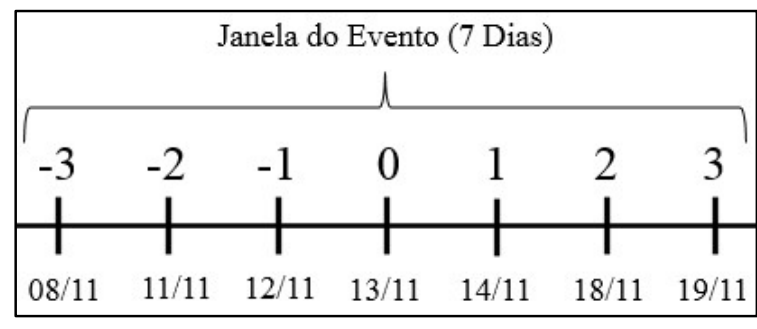

Figura 1: Janela do Evento 1.

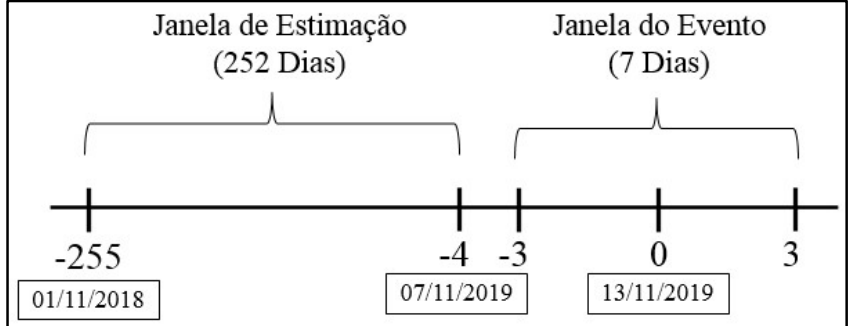

Figura 2: Janela de estimação do Evento 1.

A partir dessas definições é possível dar início aos procedimentos para determinação dos retornos esperados e anormais. Para o cálculo do retorno esperado é aplicado o método do retorno ajustado ao risco e ao mercado, que segundo Soares et al. (2002) é o mais utilizado em trabalhos apresentados em eventos no Brasil, bem como o mais sensível à captação de reações do mercado.

Este método pressupõe a estimação de uma regressão linear simples pela técnica dos mínimos quadrados ordinários (MQO) entre os retornos diários do preço das ações das empresas componentes da amostra $\left(R_{i t}\right)$ e o retorno diário de mercado $\left(R_{m t}\right)$, mensurado pela variação do Ibovespa, dos 252 dias da janela de estimação. Esses retornos diários são calculados por:

$$
\begin{aligned}
& R_{i t}=\operatorname{Ln} P_{i t} / P_{i t-1} \\
& R_{m t}=\operatorname{Ln} C_{t} / C_{t-1}
\end{aligned}
$$

Em que:

$P_{i t}$ é o preço da ação $i$ no dia $t$;

$P_{i t-1}$ é o preço da ação $i$ no dia anterior, ou seja, $t-1$;

$C_{t}$ é a cotação do Ibovespa no dia $t$;

$C_{t-1}$ é a cotação do Ibovespa no dia anterior, ou seja, $t-1$;

Ln representa o logaritmo natural que possibilita a determinação dos retornos diários considerando a capitalização contínua. De acordo com Benninga (2014) este é o melhor modo de se calcular retornos contínuos e compostos.

Estimada a regressão linear pela técnica $\mathrm{MQO}$ entre $R_{i t}$ e $R_{m t}$, os parâmetros $\alpha$ e $\beta$ são, respectivamente, o seu intercepto e coeficiente de inclinação. A Tabela 1 aponta o $\alpha$ e $\beta$ da regressão de cada ativo estimada para cada evento.

Tabela 1: Valor dos parâmetros $\alpha$ e $\beta$ por evento para cada ação da amostra.

\begin{tabular}{|l|l|l|l|l|}
\hline & VVAR3 & PCAR3 & $\boldsymbol{\beta}$ \\
\hline & $\boldsymbol{\alpha}$ & $\boldsymbol{\beta}$ & $\boldsymbol{\alpha}$ & 0,726500338 \\
\hline Evento 1 & 0,000337484 & 0,934990135 & $-0,000307256$ & 0,725365618 \\
\hline Evento 2 & 0,00171735 & 1,039878898 & $-0,00059074$ & 0,713803647 \\
\hline Evento 3 & 0,002752318 & 1,628124438 & $-0,000411118$ & \\
\hline
\end{tabular}

No método do retorno ajustado ao risco e ao mercado os retornos diários esperados para a janela de eventos $\left(E_{i t}\right)$, então, são calculados com base nos parâmetros $\alpha$ e $\beta$ estimados para o respectivo evento e nos retornos diários de mercado efetivamente observados nesse período, conforme a seguinte equação:

$$
E_{i t}=\alpha_{i}+\beta_{i} R_{m t}
$$

Calculado o retorno esperado, é possível obter o retorno anormal dos dias da janela de eventos $\left(A R_{i t}\right)$, consistente na diferença entre o retorno diário do preço da ação e o retorno esperado para o mesmo dia:

$$
A R_{i t}=R_{i t}-E_{i t}
$$


A partir do retorno anormal realiza-se procedimento de inferência estatística que pressupõe o cálculo do valor $t$, obtido pela razão entre o retorno anormal e o erro padrão dos valores preditos pela regressão estimada para o evento em questão $\left(S_{i e}\right)$ (BENNINGA, 2014):

$$
t=A R_{i t} / S_{i e}
$$

A Tabela 2 evidencia o erro padrão dos valores preditos para as regressões relativas à janela de estimação de cada evento.

Tabela 2: Valor do erro padrão por evento para cada ação da amostra.

\begin{tabular}{|l|l|l|}
\hline & VVAR3 & PCAR3 \\
\hline Erro Padrão Evento 1 & 0,029726606 & 0,017352024 \\
\hline Erro Padrão Evento 2 & 0,030168683 & 0,016782314 \\
\hline Erro Padrão Evento 3 & 0,033373417 & 0,018620712 \\
\hline
\end{tabular}

Caso o valor $t$ calculado esteja abaixo do valor $t$ crítico unicaudal que é de $-1,28,-1,64$ e $-2,33$ para, respectivamente, $10 \%, 5 \%$ e $1 \%$ de nível de significância, tem-se que o retorno anormal é estatisticamente significante (Barros et al., 2019). O valor $t$ crítico é unicaudal e negativo em função de as hipóteses predizerem um efeito negativo do evento no valor das ações.

\section{RESULTADOS E DISCUSSÃO}

Conforme se viu, os dados coletados dizem respeito às cotações diárias das ações VVAR3 e PCAR3, assim como do Ibovespa, a partir das quais se calcularam os retornos diários com base nos quais empreendeu-se o estudo de eventos. Introdutoriamente, a Tabela 3 apresenta a estatística descritiva desses retornos em função da sua posição temporal em relação a cada evento.

Tabela 3: Estatística descritiva da janela de estimação e de eventos.

\begin{tabular}{|l|l|l|l|l|l|l|l|}
\hline & & \multicolumn{2}{|l|}{ Janela de Estimação } & \multicolumn{2}{l|}{ Janela de Eventos (-3 a -1) } & \multicolumn{2}{l|}{ Janela de Eventos (0 a 3) } \\
\hline & & Média & D.P & Média & D.P & Média & D.P \\
\hline \multirow{3}{*}{ Evento 1 } & VVAR3 & $0,11 \%$ & $3,16 \%$ & $-1,52 \%$ & $2,06 \%$ & $1,24 \%$ & $4,48 \%$ \\
\cline { 2 - 8 } & PCAR3 & $0,03 \%$ & $1,94 \%$ & $-1,80 \%$ & $1,93 \%$ & $-0,10 \%$ & $1,52 \%$ \\
\cline { 2 - 8 } & Ibovespa & $0,09 \%$ & $1,19 \%$ & $-0,87 \%$ & $1,36 \%$ & $-0,21 \%$ & $0,48 \%$ \\
\hline \multirow{5}{*}{ Evento 2 } & VVAR3 & $0,26 \%$ & $3,24 \%$ & $1,05 \%$ & $1,29 \%$ & $1,57 \%$ & $5,38 \%$ \\
\cline { 2 - 8 } & PCAR3 & $0,00 \%$ & $1,87 \%$ & $0,50 \%$ & $1,17 \%$ & $0,07 \%$ & $1,41 \%$ \\
\cline { 2 - 8 } & Ibovespa & $0,09 \%$ & $1,15 \%$ & $-0,05 \%$ & $0,28 \%$ & $0,37 \%$ & $0,72 \%$ \\
\hline \multirow{3}{*}{ Evento 3 } & VVAR3 & $0,04 \%$ & $5,21 \%$ & $-0,66 \%$ & $12,49 \%$ & $2,10 \%$ & $7,60 \%$ \\
\cline { 2 - 8 } & PCAR3 & $-0,14 \%$ & $2,56 \%$ & $3,69 \%$ & $3,29 \%$ & $-2,56 \%$ & $2,93 \%$ \\
\cline { 2 - 8 } & Ibovespa & $-0,15 \%$ & $2,46 \%$ & $0,67 \%$ & $7,63 \%$ & $1,70 \%$ & $5,43 \%$ \\
\hline
\end{tabular}

Observa-se que a média dos retornos diários das ações VVAR3 e PCAR3 e o seu correspondente desvio padrão na janela de estimação possuem uma magnitude menor do que a observada em relação aos períodos das janelas de eventos. Contribui para isso a circunstância de a janela de estimação compreender uma quantidade significativamente maior de retornos diários do que a janela de eventos.

Além disso, é possível que os fluxos de informações representados pelos eventos tenham contribuído a retornos diários de maior magnitude e dispersão durante as janelas de eventos, o que é evidenciado pelas maiores médias e desvios padrões observados no período imediatamente anterior e posterior à sua ocorrência. 
Chama a atenção nesse sentido, também, o fato de os desvios padrões após os Eventos 1 e 2 terem sido bastante maiores do que nos períodos imediatamente anteriores às suas ocorrências, corroborando a interpretação do evento enquanto um fluxo de informações relevantes na medida em que ocasionou dispersão nos retornos diários dos ativos. Dinâmica contrária observou-se em relação ao Evento 3, o que pode indicar uma antecipação do fluxo de informações em relação à data formal de sua ocorrência.

Interessante notar que após a ocorrência de todos eventos os retornos médios diários de VVAR3 foram maiores do que os de PCAR3. Trata-se de indício de que os fluxos de informações contidas nos eventos foram tidos mais negativamente em relação a esse ativo do que àquele. Por outro lado, os desvios padrões desses retornos foram maiores em relação a VVAR3 do que PCAR3, o que é compreensível em virtude de as informações dizerem respeito diretamente àquela e apenas indiretamente a esta.

Importante ressalvar que à época do Evento 3 estavam ocorrendo os desdobramentos da pandemia da Covid-19, o que pode ter contribuído para a maior dispersão dos retornos diários dos ativos e do Ibovespa nesse período, representada pelos desvios padrões mais amplos nele observados. Quanto à estatística inferencial, a Tabela 4 aponta os retornos anormais e $t$ calculados por evento e correspondente dia da sua janela.

Tabela 4: Retornos anormais e $t$ calculado por evento e dia da janela de evento.

\begin{tabular}{|c|c|c|c|c|c|c|c|c|}
\hline Dia da Janela & & -3 & -2 & -1 & 0 & 1 & 2 & 3 \\
\hline \multirow[t]{4}{*}{ Evento 1} & VVAR3 & $-0,67 \%$ & $0,15 \%$ & $-1,68 \%$ & $-0,42 \%$ & $7,47 \%$ & $-0,31 \%$ & $-1,14 \%$ \\
\hline & $t$ calculado & $-0,23$ & 0,05 & $-0,57$ & $-0,14$ & 2,51 & $-0,10$ & $-0,38$ \\
\hline & PCAR3 & $-2,43 \%$ & $-0,38 \%$ & $-0,59 \%$ & $-1,75 \%$ & $-0,26 \%$ & $1,45 \%$ & $0,90 \%$ \\
\hline & $t$ calculado & $-1,40$ & $-0,22$ & $-0,34$ & $-1,01$ & $-0,15$ & 0,84 & 0,52 \\
\hline \multirow[t]{4}{*}{ Evento 2} & VVAR3 & $2,24 \%$ & $-0,18 \%$ & $0,72 \%$ & $-4,47 \%$ & $7,83 \%$ & $3,88 \%$ & $-3,18 \%$ \\
\hline & $t$ calculado & 0,74 & $-0,06$ & 0,24 & $-1,48$ & 2,60 & 1,29 & $-1,05$ \\
\hline & PCAR3 & $0,77 \%$ & $-0,46 \%$ & $1,47 \%$ & $0,73 \%$ & $-1,96 \%$ & $0,29 \%$ & $0,37 \%$ \\
\hline & $t$ calculado & 0,46 & $-0,28$ & 0,88 & 0,43 & $-1,17$ & 0,17 & 0,22 \\
\hline \multirow[t]{4}{*}{ Evento 3} & VVAR3 & $-0,02 \%$ & $-3,51 \%$ & $-2,58 \%$ & $1,03 \%$ & $-6,33 \%$ & $8,95 \%$ & $-7,42 \%$ \\
\hline & $t$ calculado & 0,00 & $-1,05$ & $-0,77$ & 0,31 & $-1,90$ & 2,68 & $-2,22$ \\
\hline & PCAR3 & $5,58 \%$ & $10,55 \%$ & $-6,39 \%$ & $-7,94 \%$ & $-7,93 \%$ & $0,56 \%$ & $0,39 \%$ \\
\hline & $t$ calculado & 3,00 & 5,67 & $-3,43$ & $-4,26$ & $-4,26$ & 0,30 & 0,21 \\
\hline
\end{tabular}

O Evento 1, que se limitou a informar a abertura de uma Investigação Independente relacionada a irregularidades contábeis, apresenta apenas dois retornos anormais estatisticamente significativos para os ativos em análise.

No dia -3 da janela de eventos (08/11/2019) PCAR3 teve um retorno anormal negativo de 2,43\%, com um $t$ calculado de $-1,40$ (nível de significância de $10 \%$ ), podendo se tratar de uma antecipação à divulgação do Fato Relevante em questão pela Via Varejo, sobretudo se considerarmos que os próximos quatro dias da janela de eventos também representaram um retorno anormal negativo a esse ativo. É compreensível uma reação negativa dos agentes de mercado em relação à cotação das ações PCAR3, na medida em que eventual constatação de irregularidades contábeis na Via Varejo poderia implicar na responsabilização da Cia Brasileira de Distribuição.

Sob a perspectiva da Via Varejo, sua ação apresentou retorno anormal negativo na Data 0, porém não significativo. Curiosamente apresentou retorno anormal positivo de 7,47\% no dia seguinte à divulgação do Fato Relevante (14/11/2019), correspondente a um t calculado de 2,51 (nível de significância de 1\%). Este 
resultado, ao contrário do esperado, indica uma reação positiva dos agentes de mercado à comunicação da abertura de uma Investigação Independente relativa a possíveis irregularidades contábeis. Essa reação pode se justificar na circunstância de recentemente ter-se alterado o controlador da Via Varejo, sendo esse comunicado da nova gestão interpretado como uma iniciativa de adoção de mecanismos de Governança Corporativa.

O Evento 2, por seu turno, detalhou a natureza das irregularidades contábeis apontadas anteriormente, tendo mencionado a presença de indícios de fraudes contábeis e falhas nos controles internos da Via Varejo, bem como indicado uma estimativa de impacto no resultado da companhia superior a R\$ 1 bilhão.

Conforme esperado, no dia deste evento a ação VVAR3 teve um retorno anormal negativo $(-4,47 \%)$ estatisticamente significativo (nível de significância de 10\%), o que evidencia uma reação inicial negativa dos agentes de mercado em relação à divulgação da existência de indícios de fraudes contábeis com impacto bilionário. De modo semelhante ao Evento 1, contudo, nos dois dias seguintes foram verificados retornos anormais positivos (7,83\% e 3,88\%, respectivamente) estatisticamente significativos (níveis de significância de $1 \%$ e $10 \%$, respectivamente). A explicação para essa reação pode estar alinhada à teorizada no Evento 1 , no sentido de ser interpretada positivamente à disposição da nova gestão em investigar a fundo as irregularidades contábeis ao ponto de desvelar fraudes contábeis e estimar seu impacto, ressalvado um choque negativo inicial.

Importante notar, também, que no dia seguinte ao Evento 2 a ação PCAR3 teve um retorno anormal negativo (-1,96\%), apesar de não significativo, em linha com o já observado no Evento 1 . Ao que parece, a reação positiva do mercado em relação à VVAR3 ocorre em detrimento da PCAR3, no sentido de que a nova gestão daquela estaria revelando irregularidades e fraudes cometidas sob o controle desta.

Por fim, o Evento 3 consiste na comunicação dos resultados da investigação, dentre os quais o apontamento de fraudes, erros e mudanças nas estimativas contábeis com impacto no resultado de $\mathrm{R} \$ 1,19$ bilhão. Este evento apresentou 8 retornos anormais significativos, sendo 5 da PCAR3 e 3 da VVAR3. É preciso considerar a ressalva já apontada de que à época da sua ocorrência estavam ocorrendo os desdobramentos da pandemia da Covid-19, o que pode ter contribuído para uma maior volatilidade dos retornos diários das ações.

De qualquer modo, observa-se que na data do evento (Data 0) PCAR3 teve seu maior retorno anormal negativo no período $(-7,94 \%)$ com $t$ calculado de $-4,26$ (nível de significância de $1 \%$ ), o que corrobora os resultados dos eventos anteriores na direção da reação negativa do mercado em relação à Cia Brasileira de Distribuição pelas fraudes ocorridas na Via Varejo S.A. durante o controle desta por aquela.

VVAR3, por seu turno, teve um retorno anormal positivo $(1,03 \%)$ e não significativo ( $t$ calculado de $0,31)$ no dia do evento, seguido por retornos anormais estatisticamente significativos negativos e positivos $(-6,33 \%, 8,95 \%$ e $-7,42 \%)$, evidenciando a incerteza dos agentes de mercado quanto a: como interpretar um impacto bilionário no resultado, sobretudo em um período de crise.

Em relação às hipóteses, portanto, apesar de a divulgação de informações relacionada à fraude 
contábil na Via Varejo S.A. ter se mostrado relevante, por ter ensejado diversos retornos anormais significativos, não é possível afirmar que afetou negativamente o retorno diário de suas ações. Isso porque, inobstante terem sido observados 2 retornos anormais negativos e significativos das ações da Via Varejo S.A. (Data 0 do Evento 2 e Data 1 do Evento 3), predominaram os 4 retornos anormais positivos e significativos (Data 1 do Evento 1, Datas 1 e 2 do Evento 2 e Data 2 do Evento 3). Deste modo, rejeita-se H1 na parte em que predizia um efeito negativo no retorno diária das ações da Via Varejo S.A.

Por outro lado, em relação à Cia Brasileira de Distribuição, a divulgação de informações relacionada à fraude contábil na Via Varejo S.A. se mostrou relevante e teve um efeito negativo sobre o retorno diário de suas ações. Com efeito, foram observados 6 retornos anormais significativos, sendo 4 negativos (Dia -3 do Evento 1 e Dias -1, 0 e 1 do Evento 3) e apenas 2 positivos (Dias -3 e -2 do Evento 3). Assim sendo, não se rejeita $\mathrm{H} 2$.

Em suma, tem-se que a divulgação de informações relacionadas à fraude contábil na Via Varejo S.A. mostrou-se relevante no que diz respeito à própria empresa e sua antiga controladora - Cia Brasileira de Distribuição -, tendo ocasionado maior dispersão dos retornos diários nas janelas de eventos, conforme evidenciado pela estatística descritiva da Tabela 3, e, também, diversos retornos anormais estatisticamente significativos observados na Tabela 4. Este achado corrobora as pesquisas anteriores de Davidson et al. (1994) e Macedo et al. (2016), no sentido da existência de conteúdo informacional e, portanto, relevância na divulgação de informações relacionadas a fraudes corporativas.

Quanto à direção da reação do mercado, os achados em relação à PCAR3 estão em linha com as pesquisas anteriores de Davidson et al. (1994) que apontou um efeito negativo junto ao mercado em função das fraudes contábeis, bem como de Macedo et al. (2016), Paul-Lawal (2016), Barros et al. (2019) e Brown et al. (2015), que indicaram reações negativas do mercado à ocorrência de atos tidos por fraudulentos.

A reação positiva dos agentes de mercado no que toca à VVAR3, por sua vez, pode estar relacionada à consequência predita por Farber (2005), segundo o qual as companhias que após o cometimento de fraudes aprimoram sua Governança Corporativa, tendem a experimentar maiores retornos no valor das suas ações. Isso porque o modo como a questão foi tratada pela Via Varejo S.A. - o qual envolveu ampla transparência, constituição de um comitê específico de investigação, além do amplo reconhecimento de fraudes e erros passados -, pode ser interpretado como um aprimoramento de mecanismos de Governança Corporativa, de modo que é possível que o mercado, desde logo, antecipe as consequências daí advindas.

\section{CONCLUSÕES}

Atento ao destaque assumido por fraudes corporativas e contábeis, bem como pela ameaça representada por essas últimas à confiança dos participantes de mercado nas demonstrações contábeis, o presente trabalho objetivou verificar a relevância da divulgação de informações pertinentes à recente fraude contábil desvelada na Via Varejo S.A.

A partir da revisão da literatura pertinente, onde se constatou a ocorrência efetiva de fraude contábil na Via Varejo S.A. e as usuais consequências negativas advindas de atos fraudulentos, foi predita em 
hipóteses a relevância da divulgação desse acontecimento associada a um efeito negativo no preço das ações das empresas envolvidas nele, quais sejam, a própria Via Varejo S.A. e a Cia Brasileira de Distribuição.

Em linha com o objetivo do trabalho e o teste das hipóteses, empreendeu-se um estudo de eventos do retorno das ações dessas empresas nas datas de divulgação das principais informaç̧ões pertinentes à fraude contábil em questão, conforme pesquisas anteriores que também se valeram deste método para aferir a relevância de determinada informação ou impacto de determinado acontecimento.

A estatística descritiva apontou que o retorno diário do preço das ações das empresas envolvidas na fraude em análise sofreu maior dispersão durante a janela dos eventos, notadamente após a ocorrência dos eventos, consubstanciados na divulgação das informações pertinentes pela Via Varejo S.A, tratando-se de indício da sua relevância. Também indicou, num primeiro momento, um efeito mais negativo às ações da Cia Brasileira de Distribuição do que da Via Varejo S.A.

A estatística inferencial, em sentido semelhante, atestou a relevância da divulgação de informações pertinentes à fraude contábil pela Via Varejo, tendo sido constatados diversos retornos anormais estatisticamente significativos das ações da Via Varejo S.A. e da Cia Brasileira de Distribuição nas janelas de eventos estabelecidas em torno daqueles acontecimentos. Apontou, portanto, valor preditivo ou confirmatório, ou ambos, em informações relacionadas ao desvelamento de fraudes contábeis.

No que toca ao impacto da fraude nas empresas envolvidas, no entanto, apenas os resultados pertinentes às ações da Cia Brasileira de Distribuição confirmaram a hipótese predita, tendo predominado os retornos anormais negativos. Em relação às ações da Via Varejo S.A., curiosamente, predominaram os retornos anormais positivos, apesar de evidências de uma reação inicial incerta dos agentes de mercado.

Teorizou-se que os retornos positivos das ações da Via Varejo S.A. ocorreram em detrimento dos retornos das ações da Cia Brasileira de Distribuição, no sentido de o mercado poder ter interpretado que a nova gestão daquela estaria desvelando irregularidades cometidas sob o controle desta. Relacionou-se esse achado a excerto da literatura que aponta retornos positivos das ações de empresas que após o cometimento de fraudes aprimoram seus mecanismos de Governança Corporativa. Com efeito, o modo como a questão foi tratada pela Via Varejo S.A., com ampla transparência, constituição de um comitê específico de investigação, bem como amplo reconhecimento de fraudes e erros passados, pode ter sido interpretado naquele sentido, tendo o mercado desde logo antecipado os efeitos daí decorrentes.

Uma limitação desse estudo diz respeito à abrangência de seus resultados, que se circunscrevem ao caso da fraude contábil na Via Varejo S.A. em análise. Nesse ponto, na verdade, reside uma sugestão para pesquisa futura que envolva o estudo de eventos de mais casos de fraudes contábeis, a fim de se possibilitarem conclusões mais generalizantes. De qualquer modo, o trabalho contribui à pesquisa contábil no que diz respeito às fraudes contábeis e suas consequências, atestando a relevância de um evento isolado e possibilitando valiosas reflexões a respeito das causas do impacto em cada uma das empresas envolvidas.

\section{REFERÊNCIAS}

ACFE. Association of Certified Fraud Examiners. Fraud tree. Austin: ACFE, 2010. 
BALL, R.; BROWN, P.. An empirical evaluation of accounting income numbers. Journal of Accounting Research, Chicago, v.6, n.2, p.159-178, 1968. DOI:

https://doi.org/10.2307/2490232

BARROS, C. M. E.; LOPES, I. F.; ALMEIDA, L. B.. Efeito contágio da operação carne fraca sobre o valor das ações dos principais players do mercado de proteínas do Brasil e do México. Enfoque: Reflexão Contábil, Curitiba, v.38, n.1, p.105-122, 2019.

BASH, A.; ALSAIFI, K.. Fear from uncertainty: An event study of Khashoggi and stock market returns. Journal of Behavioral and Experimental Finance, v.23, p.54-58, 2019. DOI: http://doi.org/10.1016/i.jbef.2019.05.004

BEASLEY, M. S. J. V.; CARCELLO, D. R.; HERMANSON; T. NEAL.. Fraudulent Financial Reporting 1998-2007: An Analysis of U.S. Public Companies. Durham: COSO, 2010.

BENNINGA, S.. Financial Modeling. 4 ed. Cambridge: MIT Press, 2014.

BINDER, J. J.. The event study methodology since 1969. Review of Quantitative Finance and Accounting, Boston, v.11, n.2, p.111-137, 1998

BORGES, S. R. P.; ANDRADE, M. E. M. C.. A opinião de especialistas sobre as variáveis relacionadas ao risco de fraude contábil no setor bancário brasileiro. Revista Universo Contábil, v.14, n.3, p.66-88, 2019.

BROWN, G. D.; CORBET, S.; MCMULLAN, C.; SHARMA, R.. Do industrial incidents in the chemical sector create equity market contagion? Journal of Safety Research, v.55, p.115119, 2015. DOI: https://doi.org/10.2139/ssrn.2447629

CAMPBELL, J. Y.; LO, A. W.; MACKINLAY, A. C.. The econometrics of financial markets. New Jersey: Princeton Press University, 1997. DOI: https://doi.org/10.1515/9781400830213

CAPLAN, D. H.; DUTTA, S. K.; MARCINKO, D. J.. Unmasking the fraud at toshiba. Issues in Accounting Education, v.34, n.3, p.41-57, 2019. DOI:

https://doi.org/10.2139/ssrn.3382076

CPC. Comitê de Pronunciamentos Contábeis.

Pronunciamento Técnico CPC 00 (R2): Estrutura Conceitual para Relatório Financeiro. Brasília: CPC, 2019.

CPC. Comitê de Pronunciamentos Contábeis. Resolução CFC n. 2016/NBCTA240(R1) de 05 de setembro de 2016: NBCTA 240 (R1). Altera a NBC TA 240 que dispõe sobre a responsabilidade do auditor em relação a fraude, no contexto da auditoria de demonstrações contábeis. Brasília: CPC, 2016.

DAVIDSON, W. N.; WORRELL, D. L.; LEE, C. I.. Stock market reactions to announced corporate illegalities. Journal of Business Ethics, v.13, n.12, p.979-987, 1994. DOI: https://doi.org/10.1007/bf00881667

DECHOW, P. M.; SLOAN, R. G.; SWEENEY, A. P.. Causes and consequences of earnings manipulation: an analysis of firms subject to enforcement actions by the SEC. Contemporary
Accouting Research, v.13, n.1, p.1-36, 1996. DOI: https://doi.org/10.1111/i.1911-3846.1996.tb00489.x

DORMINEY, J.; SCOTT FLEMING, A.; KRANACHER, M. J.; RILEY, R. A.. The evolution of fraud theory. Issues in Accounting Education, v.27, n.2, p.555-579, 2012. DOI: https://doi.org/10.2308/iace-50131

FARBER, D. B.. Restoring trust after fraud: does corporate governance matter? The Accounting Review, v.80, n.2, p.539-561, 2005. DOI: https://doi.org/10.2139/ssrn.485403

FICH, E. M.; SHIVDASANI, A.. Financial fraud, director reputation, and shareholder wealth. Journal of Financial Economics, v.86, n.2, p.306-336, 2007. DOI: https://doi.org/10.2139/ssrn.687412

GPA. Cia Brasileira de Distribuição. Comunicado ao Mercado. São Paulo: GPA, 2019.

GPA. Cia Brasileira de Distribuição. Comunicado ao Mercado. São Paulo: GPA, 2020.

KOTHARI, S. P.. Capital markets research in accounting. Journal of Accounting and Economics, v.31, p.105-231, 2001. DOI: https://doi.org/10.2139/ssrn.235798

MACEDO, M.; ALMEIDA, J.; DORNELLES, O.. Os mercados acionários internacionais reagem mais às demonstrações contábeis ou às notícias? $\mathrm{O}$ caso do escândalo do banco HSBC. Pensar Contábil, Rio de Janeiro, v.18, n.67, p.15-22, 2016.

MACKINLAY, A. C.. Event Studies in Economics and Finance. Journal of Economic Literature, v.35, n.1, p.13-39, 1997

MURCIA, F. D.; CARVALHO, L. N.. Conjecturas acerca do gerenciamento de lucros, republica o das demonstra es contábeis e fraude contábil. Contabilidade Vista \& Revista, v.1, n.4, p.61-82, 2007.

PAUL-LAWAL, O.. Effects of public sector corruption on the private sector: investigating the market value of political connections. Thesis (Doctorate in Economics) - Stanford University, California, 2016.

PEREIRA, V.. Negociação das ações da Via Varejo é suspensa após investigação. Sunoresearch, 2019.

PEROLS, J. L.; LOUGEE, B. A.. The relation between earnings management and financial statement fraud. Advances in Accounting, v.27, n.1, p.39-53, 2011. DOI: https://doi.org/10.1016/j.adiac.2010.10.004

PWC. PricewaterhouseCoopers. Pesquisa global sobre fraudes e crimes econômicos. 2018.

REZAEE, Z.. Causes, consequences, and deterence of financial statement fraud. Critical Perspectives on Accounting, v.16, n.3, p.277-298, 2005. DOI: https://doi.org/10.1016/s1045-2354(03)00072-8

ROBINS, N.. Justice will be done. In: The Corporation that changed the world: how the east India Company shaped the modern multinational. London: Pluto Press, 2012. p.122-144. 
SCOTT, W. R.. Financial accounting theory. 7 ed. Toronto: Pearson, 2015.

SMITH, A.. Uma investigação sobre a natureza e as causas da riqueza das nações. São Paulo: Hermus, 2003.

SOARES, R. O.; ROSTAGNO, L. M.; SOARES, K. T. C.. Estudo de Evento: o Método e as Formas de Cálculo do Retorno Anormal. In: ENCONTRO ANUAL DA ASSOCIAÇÃO NACIONAL DOS PROGRAMAS DE PÓSGRADUAÇÃO EM ADMINISTRAÇÃO, 27. Anais. Salvador: UFBA, 2002.

VIA VAREJO S.A.. Fato Relevante: Investigação Independente. São Caetano do Sul: VIA VAREJO S.A., 2019a.
VIA VAREJO S.A.. Fato Relevante: atualização acerca da investigação independente. São Caetano do Sul: VIA VAREJO S.A., $2019 b$.

VIA VAREJO S.A.. Fato Relevante: conclusão da investigação independente. São Caetano do Sul: VIA VAREJO S.A., 2020.

WUERGES, A. F. E.. Detecção de fraudes contábeis: é possivel quantificar os casos não-descobertos?. Dissertação (Mestrado em Administração) - Universidade Federal de Santa Catarina, Florianópolis, 2010.

A CBPC - Companhia Brasileira de Produção Científica (CNPJ: 11.221.422/0001-03) detém os direitos materiais desta publicação. Os direitos referem-se à publicação do trabalho em qualquer parte do mundo, incluindo os direitos às renovações, expansões e disseminações da contribuição, bem como outros direitos subsidiários. Todos os trabalhos publicados eletronicamente poderão posteriormente ser publicados em coletâneas impressas sob coordenação da Sustenere Publishing, da Companhia Brasileira de Produção Científica e seus parceiros autorizados. Os (as) autores (as) preservam os direitos autorais, mas não têm permissão para a publicação da contribuição em outro meio, impresso ou digital, em português ou em tradução. 